
Electronics and Instrumentation Engineering

(An ISO 3297: 2007 Certified Organization)

Vol. 4, Issue 8, August 2015

\title{
Concurrent Real and Reactive Power Flow Enhancement using UPFC in a Power Transmission System
}

\author{
R.Venkata Satish ${ }^{1}$, A.Hema Shekar ${ }^{2}$,T.Suneel Kumar ${ }^{3}$ \\ PG Student [EPS], Dept. of EEE, Sri Venkatesa Perumal College of Engineering, Puttur, Andhra Pradesh, India ${ }^{1}$ \\ Associate Professor, Dept. of EEE, Sri Venkatesa Perumal College of Engineering, Puttur, Andhra Pradesh, India ${ }^{2}$ \\ Assistant Professor, Dept. of EEE, Sri Vidyanikethan College of Engineering, Tirupathi, Andhra Pradesh, India ${ }^{3}$
}

\begin{abstract}
The paper presents simultaneous control of real and reactive power flow in a transmission network with the use of unified power flow controller (UPFC).The UPFC Provides multi-functional flexibility to solve many problems of power deliver industry. The UPFC is a combination of SSSC and STATCOM which provides concurrent real and reactive series line compensation without using external electrical energy source. The UPFC is used here to improve power transmission capability by means of unconstrained series voltage injection, transmission line voltage, impedance, load angle or alternatively the real and reactive power flow in the transmission line. This paper also deliberates the UPFC with Two Voltage Source Models (VSM). The VSM is developed in Newton Raphson (N-R) Load flow algorithm. MATLAB/SIMULINK based studies are carried out for IEEE 5-bus, IEEE 14-bus and IEEE 30bus systems showing the power flow enhancements with and without connection of UPFC. The VSM Model of UPFC along with N-R Method for these networks allows a bi-directional flow of real power between series output terminals of the SSSC and the shunt output terminals of STATCOM.
\end{abstract}

KEYWORDS: Unified Power Flow Controller (UPFC), Newton Raphson (N-R) Method, Voltage Source Model (VSM), power flow studies, SSSC, STATCOM, MATLAB/SIMULINK, Power Transmission System..

\section{I.INTRODUCTION}

IN ac power systems, with insufficient electrical storage, the electrical generation and load must balance at all times. To some extent, the electrical system is self regulating. If generation is less than load, the voltage and frequency drop, and there by the load, goes down to equal the generation minus the transmission losses. With reactive power support the load voltage will grow up with frequency drop and collapsing the system. So power flow control is necessary in a transmission line. FACTS controllers provides variety of power flow controls based on requirements. There are two distinctly different technical approaches to the realization of controllers used in transmission line compensation. The controllers like static Var compensator (SVC), Thyristor controlled series capacitors (TCSC) and Thyristor control voltage and phase angle regulators(TCVR \& TCPAR) which are used either for reactive compensators or to exchange real power only but the controllers like STATCOM ,SSSC and Static synchronous voltage and angle regulators are analogues to those of ideal synchronous machines with inherent capabilities of exchanging of both real and reactive power and to automatically generates or absorbs the reactive power.

The STATCOM and SSSC are implemented by voltage source converter where operated as asynchronous voltage source used for effective voltage and power flow control in a self sufficient manner by internally generated shunt and series reactive compensation. However voltage and phase angle control involves the exchange of both reactive and real power. So for effective voltage and power flow control a FACTS controller need to operate in all four quadrants either of the complex $\mathrm{P}+\mathrm{jQ}$ plane. To realize this two voltage source converters one operated in series and another operated in shunt with a common DC capacitor in a back to back connection is necessary. The series converter internally generates the reactive power component of the VA but transfers the separated real power component to the common DC link. The shunt converter supplies or absorbs the real power component from the dc link and transfer it back to the AC system .with the real power support of the shunt converter, the series converter operates as an ideal synchronous generator 


\title{
International Journal of Advanced Research in Electrical, Electronics and Instrumentation Engineering
}

\author{
(An ISO 3297: 2007 Certified Organization)
}

\section{Vol. 4, Issue 8, August 2015}

capable of supplying or absorbing both real and reactive power. This multifunctional back to back voltage source converter arrangement is called Unified Power Flow Controller (UPFC). The UPFC was devised for the real time control and dynamic compensation of transmission system of providing flexible control of all parameters effecting power flow in the transmission line like voltage, impedance and phase angle.

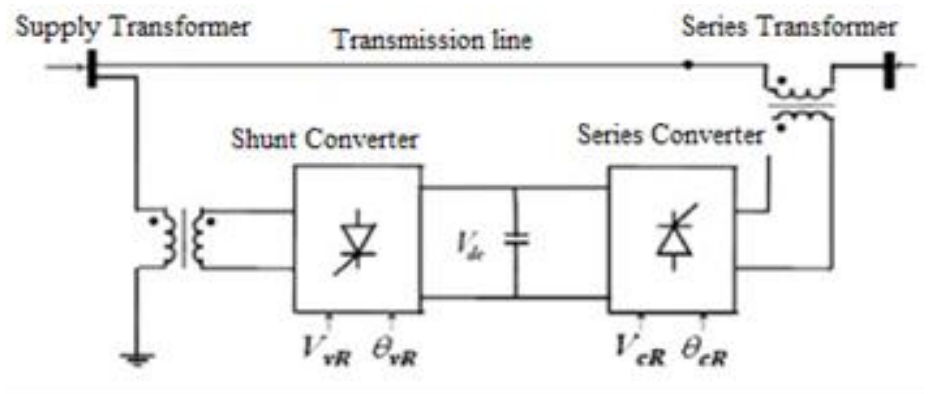

Fig. 1: UPFC Model with shunt and Series VSCs

The objective of this paper is to investigate Improvement of real and reactive power flows in an IEEE 5 bus, 14 bus and 30 bus system using UPFC. The upfc is incorporated in between 1-2 bus of the above slandered IEEE bus systems. The operation of UPFC provides stand point of traditional power transmission based on reactive shunt compensation, series compensation and phase angle regulation and thereby meets multiple control objectives by adding the injected voltage with appropriate magnitude and phase angle to the sending end bus terminal voltage. The power flow concept for the above said IEEE bus configurations the UPFC is incorporated and represented by two voltage sources called Voltage Source Model (VSM). This model of UPFC is implemented through Newton Raphson algorithm to estimate the power Flow control.

\section{PERFORMANCE OF UPFC IN A SIMPLE TWO MACHINE SYSTEM}

\section{II.I Basic Operating Principle of UPFC}

As the load flow studies for any power transmission system needs the representation of unknown parameters for a specified bus in an interconnected system with n number of buses. Here the upfc is represented and explained for a two machine system.

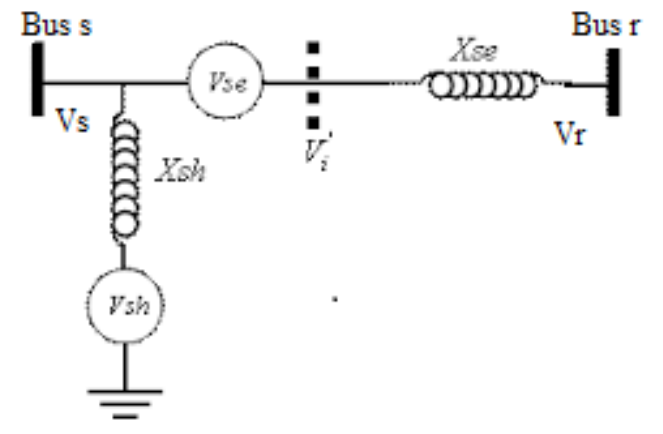

Fig. 2: Basic configuration of Two Voltage Source Model

Generally an UPFC is considered to be a synchronous voltage source (SVS) represented as a controlled voltage phasor of a controllable magnitude $\mathrm{V}_{\mathrm{mn}}\left(0 \leq \mathrm{V}_{\mathrm{mn}} \leq \mathrm{V}_{\mathrm{mn}} \max \right)$ and angle $\theta(0 \leq \theta \leq 2 \pi)$ in series with the transmission line. The UPFC as a SVS exchanges fundamental frequency (power system frequency) $V_{m n}$ with both reactive and real power with the transmission line, for above need the SVS requires a suitable power supply or sink but an UPFC exchanges the real power with one of the end bus. The UPFC is designed with two voltage source converters connected back to back through a common DC link provided by a DC storage capacitor. The real power can flow in either direction between 


\title{
International Journal of Advanced Research in Electrical, Electronics and Instrumentation Engineering
}

\author{
(An ISO 3297: 2007 Certified Organization)
}

\section{Vol. 4, Issue 8, August 2015}

the AC terminals with the operation of two converters. Each converter can independently compensate the reactive power required at $\mathrm{AC}$ terminals.

The series converter operates to inject the synchronized control voltage $V_{m n}$ with specified magnitude and phase angle in series to the line through an insertion transformer. The shunt connected converter is operated to supply real power demand required by series converter. This converter maintained a steady DC voltage and the net real power drawn from the ac system is equal to the losses of two converters plus the losses present in the coupling transformers'. The shunt converter functions like a STATCOM and regulates the terminal voltage at the bus terminals by generating or absorbing the required reactive power. To have the power flow control the UPFC can be operated in four different modes as per the system requirements.
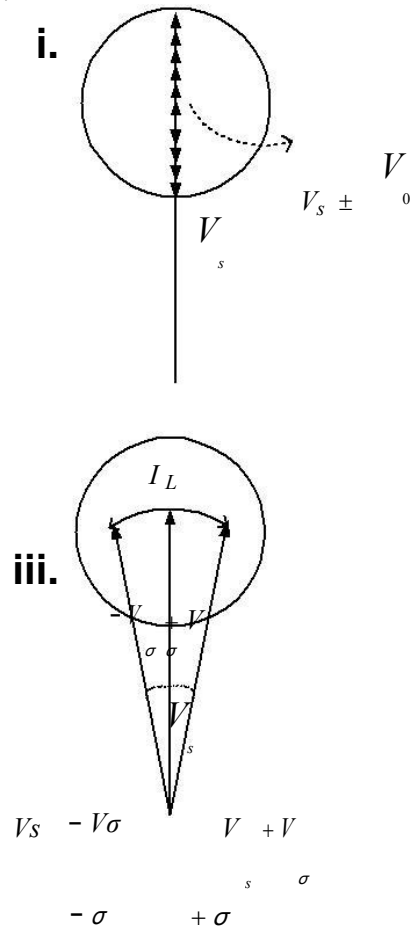

ii.

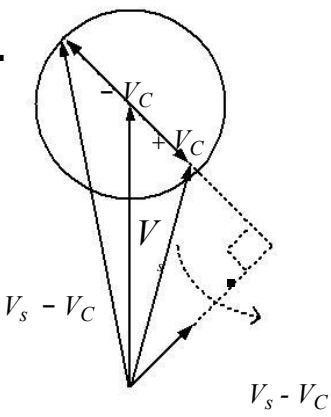

iv.

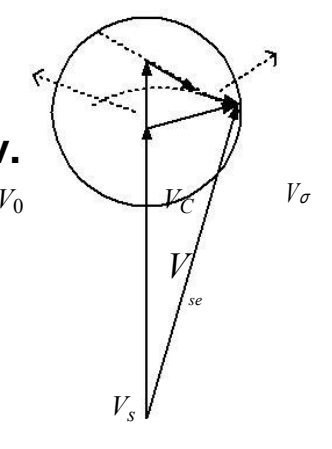

$V_{s}+V_{s e}$

Fig.3: shows four different modes of operations of UPFC with i) terminal voltage regulation, ii) Line impedance compensation, iii) Phase shifting and iv) terminal voltage, Impedance and phase angle regulation.

In this paper the concurrent real and reactive power flow improvements are obtained by operating the UPFC with terminal voltage and phase angle regulation. The UPFC generated voltage $\mathrm{V}_{\mathrm{mn}}$ is the combination of voltage regulated component $\Delta \mathrm{V} 0$ and phase shifting voltage component $\mathrm{V}_{\theta}$ where this voltage component changes the phase angle of the regulated voltage phasor $\mathrm{V}_{0}+\Delta \mathrm{V}_{0}$ by an angle $\theta$.

\section{II.II MATHEMATICAL MODELING OF UPFC WITH TERMINAL VOLTAGE AND PHASE ANGLE REGULATION}

A UPFC is placed between the Bus s and Bus $r$ in the power transmission system. From the mathematical modeling purpose of read, the set of nonlinear, algebraic equations that describe the wattage network underneath the steady state conditions were resolved for the power flow solutions. Many approaches are argue to unravel for the facility load flow equations. In beginning, approaches were supported the loop equations and methods mistreatment Gauss-type solutions. This technique was hard as a result of the network loops should be specific by hand by the systems engineer. The disadvantage of those algorithms is that they reveal poor convergence characteristics once applied to the answer of the networks. to beat such limitations, the Newton-Raphson technique and derived formulations were developed. 


\section{International Journal of Advanced Research in Electrical,} Electronics and Instrumentation Engineering

\section{(An ISO 3297: 2007 Certified Organization)}

\section{Vol. 4, Issue 8, August 2015}

The mathematical modeling equations can be obtained by applying KCL at all the nodes in Two Voltage Source

Model. By applying the Kirchhoff's current and the voltage laws for the network gives:

$$
\left[\begin{array}{c}
I_{s} \\
I_{r}
\end{array}\right]=\left[\begin{array}{cccc}
Y_{s e}+Y_{s h} & -Y_{s e} & -Y_{s e} & -Y_{s h} \\
-Y_{s e} & Y_{s e} & Y_{s e} & o
\end{array}\right]\left[\begin{array}{c}
V_{s} \\
V_{r} \\
V_{s e} \\
V_{s h}
\end{array}\right]
$$

$\mathrm{I}_{s}=\left(\mathrm{Y}_{\mathrm{se}}+\mathrm{Y}_{\mathrm{sh}}\right) \mathrm{V}_{\mathrm{s}}-\mathrm{V}_{\mathrm{r}} \mathrm{Y}_{\mathrm{se}}-\mathrm{V}_{\mathrm{se}} \mathrm{Y}_{\mathrm{se}}-\mathrm{V}_{\mathrm{sh}} \mathrm{Y}_{\mathrm{sh}}$

$I_{\mathrm{r}}=-\mathrm{V}_{\mathrm{se}} \mathrm{Y}_{\mathrm{se}}+\mathrm{V}_{\mathrm{r}} \mathrm{Y}_{\mathrm{se}}+\mathrm{V}_{\mathrm{se}} \mathrm{Y}_{\mathrm{se}}$

Multiply (3.1) and (3.2) with their respective bus voltage to get the apparent powers of Bus s and Bus r.

Apparent power of Bus s:

$$
\begin{aligned}
& S_{s}=V_{s} * I_{s} \mathrm{~S}_{\mathrm{s}}=\mathrm{V}_{\mathrm{se}}{ }^{2}\left(\mathrm{Y}_{\mathrm{se}}+\mathrm{Y}_{\mathrm{sh}}\right)-\mathrm{V}_{\mathrm{s}} \mathrm{V}_{\mathrm{r}} \mathrm{Y}_{\mathrm{se}}-\mathrm{V}_{\mathrm{s}} \mathrm{V}_{\mathrm{se}} \mathrm{Y}_{\mathrm{se}}-\mathrm{V}_{\mathrm{s}} \mathrm{V}_{\mathrm{sh}} \mathrm{Y}_{\mathrm{se}} \\
& \mathrm{S}_{\mathrm{s}}=\mathrm{V}_{\mathrm{se}}{ }^{2}\left(\mathrm{Y}_{\mathrm{se}}+\mathrm{Y}_{\mathrm{sh}}\right)-\mathrm{V}_{\mathrm{s}} \mathrm{V}_{\mathrm{r}} \mathrm{Y}_{\mathrm{se}}-\mathrm{V}_{\mathrm{s}} \mathrm{V}_{\mathrm{se}} \mathrm{Y}_{\mathrm{se}}-\mathrm{V}_{\mathrm{s}} \mathrm{V}_{\mathrm{sh}} \mathrm{Y}_{\mathrm{se}}
\end{aligned}
$$

Real and Reactive power at Bus s:

$$
\begin{aligned}
\mathrm{P}_{\mathrm{s}}= & \mathrm{V}_{\mathrm{s}}{ }^{2} \mathrm{G}_{\mathrm{ss}}+\mathrm{V}_{\mathrm{s}} \mathrm{V}_{\mathrm{r}}\left(\mathrm{G}_{\mathrm{sr}} \cos \left(\theta_{\mathrm{s}}-\theta_{\mathrm{r}}\right)+\mathrm{B}_{\mathrm{sr}} \operatorname{Sin}\left(\theta_{\mathrm{s}}-\theta_{\mathrm{r}}\right)\right) \\
& +\mathrm{V}_{\mathrm{s}} \mathrm{V}_{\mathrm{se}}\left(\mathrm{G}_{\mathrm{sr}} \operatorname{Cos}\left(\theta_{\mathrm{s}}-\theta_{\mathrm{se}}\right)+\mathrm{B}_{\mathrm{sr}} \sin \left(\theta_{\mathrm{s}}-\theta_{\mathrm{se}}\right)\right) \\
& +\mathrm{V}_{\mathrm{s}} \mathrm{V}_{\mathrm{sh}}\left(\mathrm{G}_{\mathrm{sh}} \operatorname{Cos}\left(\theta_{\mathrm{s}}-\theta_{\mathrm{sh}}\right)+\mathrm{B}_{\mathrm{sh}} \operatorname{Sin}\left(\theta_{\mathrm{s}}-\theta_{\mathrm{sh}}\right)\right) \\
\mathrm{Q}_{\mathrm{s}}= & -\mathrm{V}_{\mathrm{s}}^{2} \mathrm{~B}_{\mathrm{ss}}+\mathrm{V}_{\mathrm{s}} \mathrm{V}_{\mathrm{r}}\left(\mathrm{G}_{\mathrm{sr}} \sin \left(\theta_{\mathrm{s}}-\theta_{\mathrm{r}}\right)-\mathrm{B}_{\mathrm{sr}} \operatorname{Cos}\left(\theta_{\mathrm{s}}-\theta_{\mathrm{r}}\right)\right) \\
& +\mathrm{V}_{\mathrm{s}} \mathrm{V}_{\mathrm{se}}\left(\mathrm{G}_{\mathrm{sr}} \operatorname{Sin}\left(\theta_{\mathrm{s}}-\theta_{\mathrm{se}}\right)-\mathrm{B}_{\mathrm{sr}} \cos \left(\theta_{\mathrm{s}}-\theta_{\mathrm{se}}\right)\right) \\
& +\mathrm{V}_{\mathrm{s}} \mathrm{V}_{\mathrm{sh}}\left(\mathrm{G}_{\mathrm{sh}} \sin \left(\theta_{\mathrm{s}}-\theta_{\mathrm{sh}}\right)-\mathrm{B}_{\mathrm{sh}} \cos \left(\theta_{\mathrm{s}}-\theta_{\mathrm{sh}}\right)\right)
\end{aligned}
$$

Real and Reactive power of shunt converter:

$$
\begin{aligned}
& \mathrm{P}_{\mathrm{sh}}=\mathrm{V}_{\mathrm{sh}}{ }^{2} \mathrm{G}_{\mathrm{sh}}+\mathrm{V}_{\mathrm{sh}} \mathrm{V}_{\mathrm{s}}\left(\mathrm{G}_{\mathrm{sh}} \cos \left(\theta_{\mathrm{sh}}-\theta_{\mathrm{s}}\right)+\mathrm{B}_{\mathrm{sh}} \operatorname{Sin}\left(\theta_{\mathrm{sh}}-\theta_{\mathrm{s}}\right)\right) \\
& \mathrm{Q}_{\mathrm{sh}}=-\mathrm{V}_{\mathrm{sh}}{ }^{2} \mathrm{~B}_{\mathrm{sh}}+\mathrm{V}_{\mathrm{sh}} \mathrm{V}_{\mathrm{k}}\left(\mathrm{G}_{\mathrm{sh}} \sin \left(\theta_{\mathrm{sh}}-\theta_{\mathrm{s}}\right)-\mathrm{B}_{\mathrm{sh}} \operatorname{Cos}\left(\theta_{\mathrm{sh}}-\theta_{\mathrm{s}}\right)\right)
\end{aligned}
$$

Apparent power of Bus r: 


\section{International Journal of Advanced Research in Electrical, Electronics and Instrumentation Engineering}

(An ISO 3297: 2007 Certified Organization)

Vol. 4, Issue 8, August 2015

$$
\begin{aligned}
\mathrm{S}_{\mathrm{r}} & =\mathrm{V}_{\mathrm{r}} * \mathrm{I}_{\mathrm{r}} \\
& =-\mathrm{V}_{\mathrm{s}} \mathrm{V}_{\mathrm{r}} \mathrm{Y}_{\mathrm{se}}+\mathrm{V}_{\mathrm{r}}{ }^{2} \mathrm{Y}_{\mathrm{se}}+\mathrm{V}_{\mathrm{r}} \mathrm{V}_{\mathrm{se}} \mathrm{Y}_{\mathrm{se}}
\end{aligned}
$$

Real and Reactivepow er at Bus $r$ :

$$
\begin{aligned}
\mathrm{P}_{\mathrm{r}}= & \mathrm{V}_{\mathrm{r}}^{2} \mathrm{G}_{\mathrm{rr}}+\mathrm{V}_{\mathrm{r}} \mathrm{V}_{\mathrm{s}}\left(\mathrm{G}_{\mathrm{rs}} \cos \left(\theta_{\mathrm{r}}-\theta_{\mathrm{s}}\right)+\mathrm{B}_{\mathrm{rs}} \operatorname{Sin}\left(\theta_{\mathrm{r}}-\theta_{\mathrm{s}}\right)\right) \\
& +\mathrm{V}_{\mathrm{r}} \mathrm{V}_{\mathrm{se}}\left(\mathrm{G}_{\mathrm{rr}} \operatorname{Cos}\left(\theta_{\mathrm{r}}-\theta_{\mathrm{se}}\right)+\mathrm{B}_{\mathrm{rr}} \operatorname{Sin}\left(\theta_{\mathrm{r}}-\theta_{\mathrm{se}}\right)\right) \\
\mathrm{Q}_{\mathrm{r}}= & -\mathrm{V}_{\mathrm{r}}^{2} \mathrm{~B}_{\mathrm{rr}}+\mathrm{V}_{\mathrm{r}} \mathrm{V}_{\mathrm{s}}\left(\mathrm{G}_{\mathrm{rs}} \sin \left(\theta_{\mathrm{r}}-\theta_{\mathrm{s}}\right)-\mathrm{B}_{\mathrm{rs}} \operatorname{Cos}\left(\theta_{\mathrm{r}}-\theta_{\mathrm{s}}\right)\right) \\
& +\mathrm{V}_{\mathrm{r}} \mathrm{V}_{\mathrm{se}}\left(\mathrm{G}_{\mathrm{rr}} \operatorname{Sin}\left(\theta_{\mathrm{r}}-\theta_{\mathrm{se}}\right)-\mathrm{B}_{\mathrm{rr}} \cos \left(\theta_{\mathrm{r}}-\theta_{\mathrm{se}}\right)\right)
\end{aligned}
$$

Real and Reactivepow er of series converter:

$$
\begin{aligned}
\mathrm{P}_{\mathrm{se}}= & \mathrm{V}_{\mathrm{se}}^{2} \mathrm{G}_{\mathrm{rr}}+\mathrm{V}_{\mathrm{se}} \mathrm{V}_{\mathrm{s}}\left(\mathrm{G}_{\mathrm{sr}} \cos \left(\theta_{\mathrm{se}}-\theta_{\mathrm{s}}\right)+\mathrm{B}_{\mathrm{sr}} \operatorname{Sin}\left(\theta_{\mathrm{se}}-\theta_{\mathrm{s}}\right)\right) \\
& +\mathrm{V}_{\mathrm{se}} \mathrm{V}_{\mathrm{r}}\left(\mathrm{G}_{\mathrm{rr}} \operatorname{Cos}\left(\theta_{\mathrm{se}}-\theta_{\mathrm{r}}\right)+\mathrm{B}_{\mathrm{rr}} \operatorname{Sin}\left(\theta_{\mathrm{se}}-\theta_{\mathrm{r}}\right)\right) \\
\mathrm{Q}_{\mathrm{r}}= & -\mathrm{V}_{\mathrm{se}}{ }^{2} \mathrm{~B}_{\mathrm{rr}}+\mathrm{V}_{\mathrm{se}} \mathrm{V}_{\mathrm{s}}\left(\mathrm{G}_{\mathrm{sr}} \operatorname{Sin}\left(\theta_{\mathrm{se}}-\theta_{\mathrm{s}}\right)-\mathrm{B}_{\mathrm{sr}} \operatorname{Cos}\left(\theta_{\mathrm{se}}-\theta_{\mathrm{s}}\right)\right) \\
& +\mathrm{V}_{\mathrm{se}} \mathrm{V}_{\mathrm{r}}\left(\mathrm{G}_{\mathrm{rr}} \operatorname{Sin}\left(\theta_{\mathrm{se}}-\theta_{\mathrm{r}}\right)-\mathrm{B}_{\mathrm{rr}} \cos \left(\theta_{\mathrm{se}}-\theta_{\mathrm{r}}\right)\right)
\end{aligned}
$$

\section{IMPLEMENTATION OF UPFC USING NEWTON RAPSONS ALGORITHM AND FLOW CHART}

The projected algorithmic rule for resolution power flow drawback placed with UPFC is enforced by N-R technique. The program is named as "unified power flow controller load flow" (UPFCLF). Fig.4 depicts the load flow diagram of the programming method. Overall procedure of the projected algorithmic rule are often summarized as follows: The input system information includes the fundamental system information needed for standard power flow computation that is the number and kinds of buses, conductor information, generation and load information, the situation of UPFC and therefore the values of UPFC management parameters. System admittance matrix and traditional Jacobian matrix is created as a result of incoming of UPFC. At following step, Jacobin matrix is modified and power equations are mismatched. And then bus voltages are updated at every iteration. Convergence is checked whether or not achieved or not; if no, Jacobin matrix is changed and power equations are mismatched till convergence is achieved. If yes, power flow results are displayed.

\section{Steps to Solve the Newton-Raphson Algorithm}

Step 1: Read the input of the system information that includes the info required for standard power flow calculation, i.e., the quantity and types of buses, conductor information, generation, load information and placement of UPFC and the management variables of UPFC.

Step 2: Formation of admittance matrix $Y_{\text {bus }}$ of the line between the bus's' and ' $r$ '.

Step 3: Combining the UPFC power equations with network equation, we get the conventional power flow equation. Step 4: The conventional Jacobin matrix are formed $\left(\mathrm{P}_{i}^{\mathrm{s}}\right.$ and $\left.\mathrm{Q}_{\mathrm{i}}^{\mathrm{s}}\right)$ due to the inclusion of UPFC. The insertion of these variables increases the dimensions of the Jacobin matrix.

Step 5: In this step, the Jacobin matrix was modified and power equations square measure mismatched.

Step 6: In this step, the Jacobin matrix was modified and power equations square measure mismatched.

Step 7: If convergence isn't achieved within the next step the algorithmic program goes back to the step 6 and

Therefore the Jacobin matrix is changed and therefore the power equations were mismatched till convergence was earned.

Step 8: If the convergence achieved in Step 7, the output load flow was calculated for PQ bus that features the Bus bars voltages, generation, transmission line flow and losses 
International Journal of Advanced Research in Electrical, Electronics and Instrumentation Engineering

(An ISO 3297: 2007 Certified Organization)

Vol. 4, Issue 8, August 2015

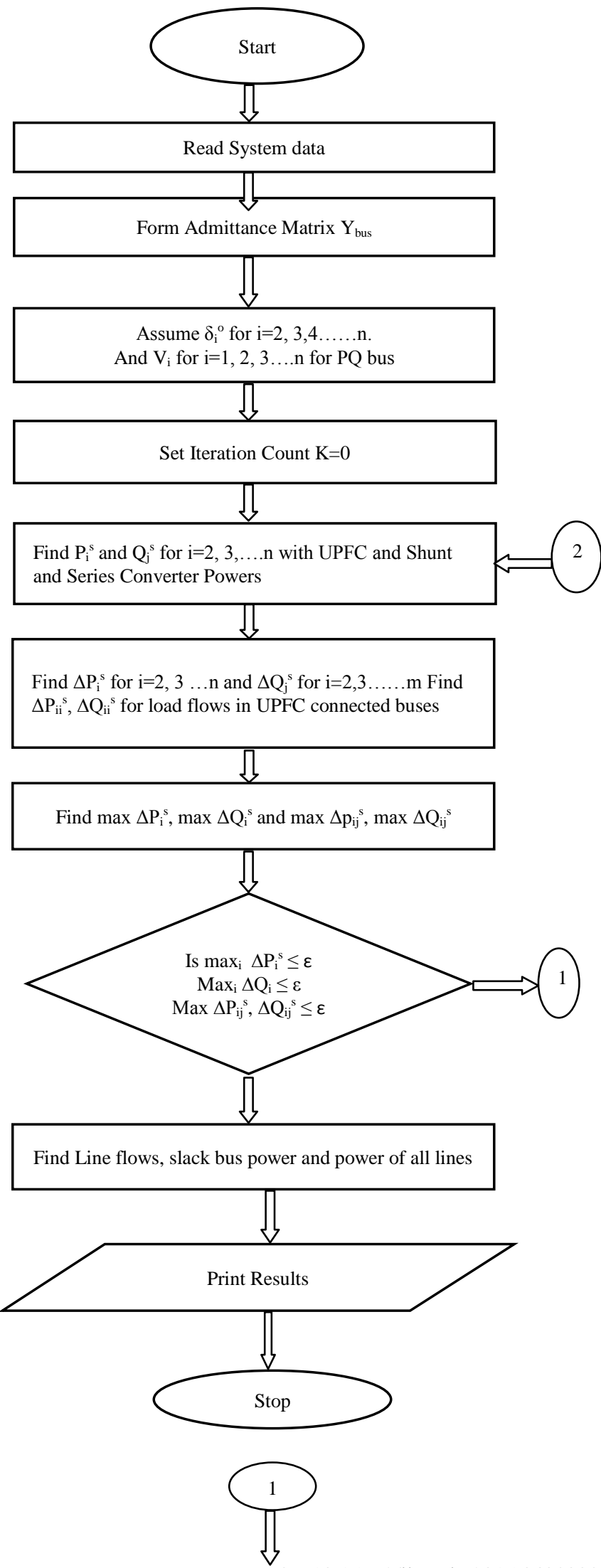




\section{International Journal of Advanced Research in Electrical, Electronics and Instrumentation Engineering}

(An ISO 3297: 2007 Certified Organization)

Vol. 4, Issue 8, August 2015

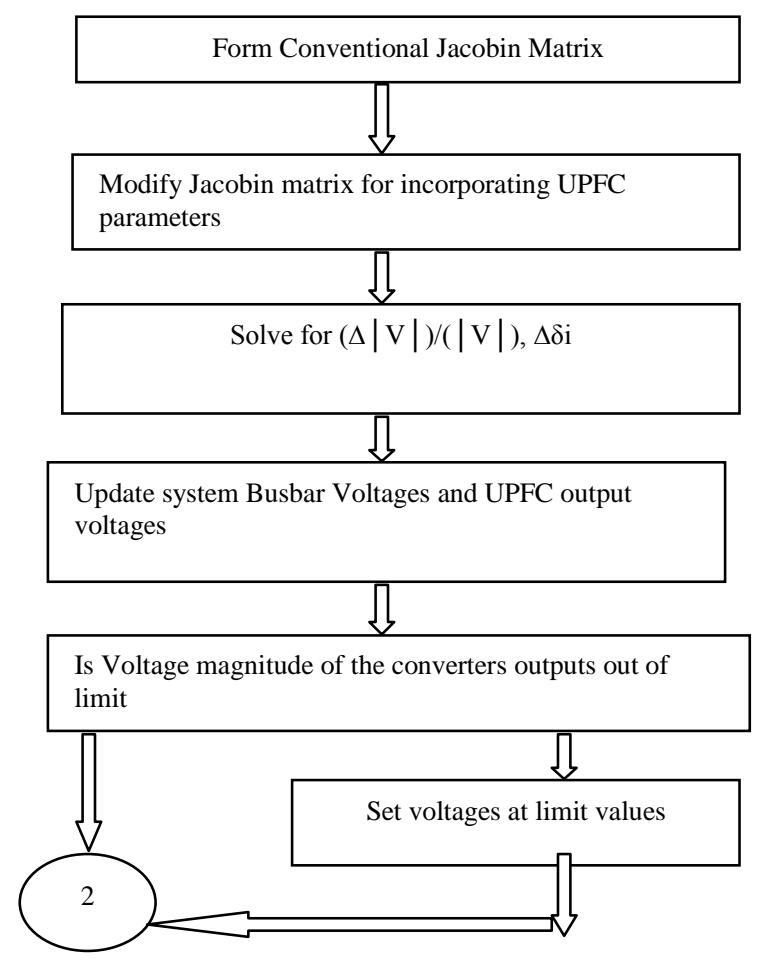

Fig 5: Flow chart for implementation of UPFC

\section{TEST CASE AND SIMULATION}

In order to research the practicableness of the projected technique, an outsized variety of power systems completely different of various sizes and underneath different system conditions has been tested. It should be got wind that the results square measure underneath supposed traditional power flow, i.e. the management parameters of UPFC are given and UPFC is operated in an closed -loop kind. All the results indicate sensible convergence and high accuracy achieved by the projected methodology. During this section, the 14- bus sensible system is conferred to numerically demonstrate its performance. It are accustomed show quantitatively, however the UPFC performs. The initial network is changed to incorporate the UPFC. This compensates the road between any of the buses. The UPFC is employed to manage the active and reactive power flowing within the line at a pre- such worth. The load flow answer for the changed network is obtained by the projected power flow algorithmic rule and the Matlab program is employed to seek out the losses between any buses and the ability flow between the lines square measure determined the effects of UPFC. An equivalent procedure is continual to look at the losses between the buses. An IEEE 5 bus system structure is shown in fig 6.

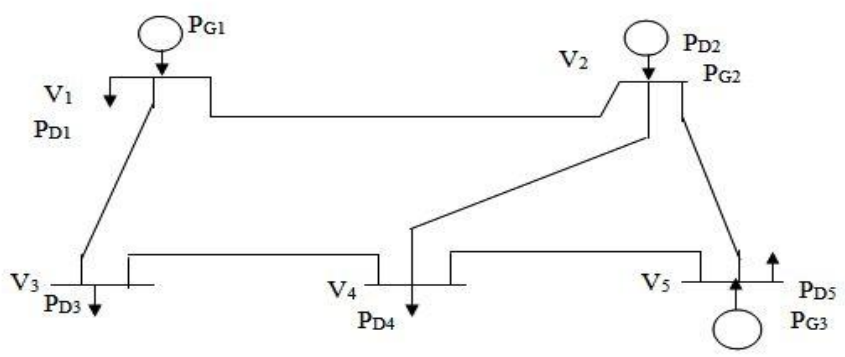

Fig. 6: IEEE 5 Bus System 


\section{International Journal of Advanced Research in Electrical, Electronics and Instrumentation Engineering}

(An ISO 3297: 2007 Certified Organization)

\section{Vol. 4, Issue 8, August 2015}

An IEEE 14 -Bus system structure in a power transmission system is shown fig 7.

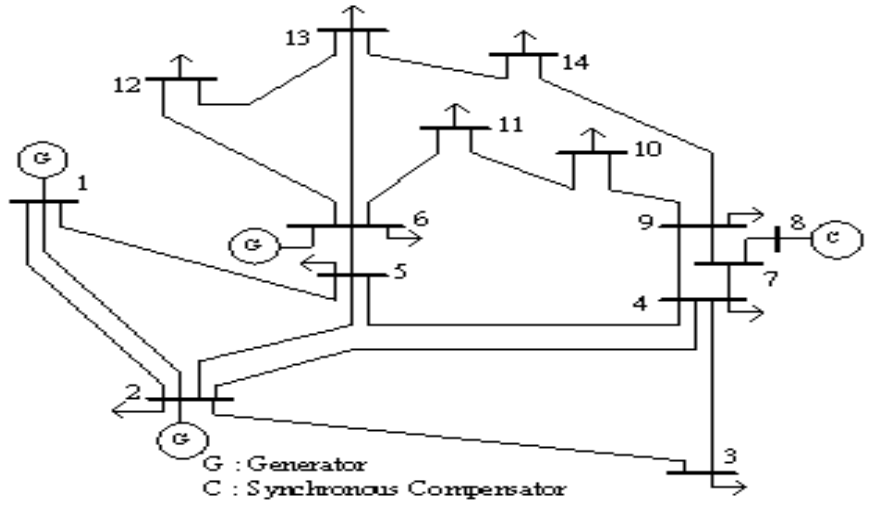

Fig. 7: IEEE 14 Bus Systems

\section{RESULT AND DISCUSSION}

The network was tested without UPFC and with UPFC. And it was observed that the UPFC parameters were within limits. The simulation shows the power flow for the line active and reactive powers and reduces the total power losses which are tabulated below. The voltages of the buses with and without UPFC are also tabulated:

The magnitude of the voltages at different buses are observed when UPFC is not connected in the IEEE 5 Bus power transmission system and compared with the magnitude of the voltages when UPFC is connected in the IEEE 5 Bus system between the lines of 1 and 2 and tabulated below.

Table 1: VOLTAGE profile of IEEE 5 Bus with and without UPFC

\begin{tabular}{|c|c|c|c|c|c|c|}
\hline \multirow{2}{*}{ BUS } & \multicolumn{2}{|c|}{ VOLTAGE PROFILE -WITHOUT UPFC } & \multicolumn{2}{c|}{ VOLTAGE PROFILE -WITH UPFC } \\
\cline { 2 - 7 } & VOLTAGE & ANGLE(rad) & ANGLE(deg) & VOLTAGE & ANGLE(rad) & ANGLE(deg) \\
\hline 1 & 1.060000 & 0.000000 & 0.000000 & 1.060000 & 0.000000 & 0.000000 \\
\hline 2 & 0.995004 & -0.037489 & -2.147973 & 1.012802 & -0.021868 & -1.252917 \\
\hline 3 & 0.987625 & -0.087646 & -5.021758 & 1.006397 & -0.068236 & -3.909631 \\
\hline 4 & 0.982968 & -0.093511 & -5.357788 & 1.004389 & -0.071523 & -4.097976 \\
\hline 5 & 0.967789 & -0.104355 & -5.979102 & 1.013454 & -0.057244 & -3.279815 \\
\hline
\end{tabular}

The magnitude of the active and reactive powers at different buses are observed when UPFC is not connected in the IEEE 5 Bus power transmission system and compared with the magnitude of the active and reactive powers when UPFC is connected in the IEEE 5 Bus system between the lines of 1 and 2 and tabulated below.

Table 2: POWER FLOW profile of IEEE 5 Bus with and without UPFC

\begin{tabular}{|c|c|c|c|c|c|c|}
\hline \multirow{2}{*}{$\begin{array}{c}\text { BUS } \\
\text { CODE }\end{array}$} & \multicolumn{3}{|c|}{ POWER FLOW BETWEEN LINES - without } & \multicolumn{3}{c|}{ POWER FLOW BETWEEN LINES - } \\
\cline { 2 - 7 } & REAL POWER & $\begin{array}{c}\text { REACTIVE } \\
\text { POWER }\end{array}$ & LOSS & $\begin{array}{c}\text { REAL } \\
\text { POWER }\end{array}$ & $\begin{array}{c}\text { REACTIVE } \\
\text { POWER }\end{array}$ & LOSS \\
\hline $1-2$ & 0.941144 & 0.813184 & 0.028533 & 0.603549 & 0.603215 & 0.013705 \\
\hline $1-3$ & 0.417353 & 0.256140 & 0.006808 & 0.328817 & 0.177900 & 0.004020 \\
\hline $2-3$ & 0.260638 & -0.059023 & 0.004210 & 0.248866 & -0.061343 & 0.003720 \\
\hline
\end{tabular}




\section{International Journal of Advanced Research in Electrical, Electronics and Instrumentation Engineering}

(An ISO 3297: 2007 Certified Organization)

\section{Vol. 4, Issue 8, August 2015}

\begin{tabular}{|l|l|l|l|l|l|l|}
\hline $2-4$ & 0.296338 & -0.043518 & 0.005356 & 0.268748 & -0.055794 & 0.004297 \\
\hline $2-5$ & 0.555635 & 0.043536 & 0.012611 & 0.272230 & -0.106281 & 0.003212 \\
\hline $3-4$ & 0.216973 & 0.071809 & 0.000551 & 0.119943 & 0.017422 & 0.000150 \\
\hline $4-5$ & 0.057404 & 0.019111 & 0.000428 & -0.065757 & -0.040806 & 0.000362 \\
\hline
\end{tabular}

The magnitude of the voltages at different buses are observed when UPFC is not connected in the IEEE 14 Bus power transmission system and compared with the magnitude of the voltages when UPFC is connected in the IEEE 14 Bus system between the lines of 1 and 2 and tabulated below.

Table 3: voltage profile of IEEE 14 Bus with and without UPFC

\begin{tabular}{|c|c|c|c|c|c|c|}
\hline \multirow{2}{*}{ BUS } & \multicolumn{2}{|c|}{ VOLTAGE PROFILE -WITH OUT UPFC } & \multicolumn{2}{c|}{ VOLTAGE PROFILE -WITH UPFC } \\
\cline { 2 - 7 } & VOLTAGE & ANGLE(rad) & ANGLE(deg) & VOLTAGE & ANGLE(rad) & ANGLE(deg) \\
\hline 1 & 1.060000 & 0.000000 & 0.000000 & 1.060000 & 0.000000 & 0.000000 \\
\hline 2 & 0.985771 & -0.075402 & -4.320190 & 1.001845 & -0.062710 & -3.593030 \\
\hline 3 & 0.903126 & -0.223980 & -12.833113 & 0.928323 & -0.196953 & -11.284568 \\
\hline 4 & 0.921461 & -0.174810 & -10.015860 & 0.951845 & -0.143809 & -8.239624 \\
\hline 5 & 0.936978 & -0.146366 & -8.386177 & 0.970176 & -0.112318 & -6.435364 \\
\hline 6 & 0.868920 & -0.278955 & -15.982950 & 0.904532 & -0.237160 & -13.588261 \\
\hline 7 & 0.876830 & -0.250193 & -14.335005 & 0.909947 & -0.213043 & -12.206489 \\
\hline 8 & 0.876830 & -0.250193 & -14.335005 & 0.909947 & -0.213043 & -12.206489 \\
\hline 9 & 0.855507 & -0.292879 & -16.780731 & 0.889781 & -0.251984 & -14.437645 \\
\hline 10 & 0.848724 & -0.298066 & -17.077906 & 0.883572 & -0.256407 & -14.691030 \\
\hline 11 & 0.854467 & -0.291992 & -16.729910 & 0.889830 & -0.249989 & -14.323328 \\
\hline 12 & 0.850666 & -0.301348 & -17.265991 & 0.886929 & -0.257952 & -14.779539 \\
\hline 13 & 0.845023 & -0.303217 & -17.373048 & 0.881353 & -0.259780 & -14.884317 \\
\hline 14 & 0.828357 & -0.324395 & -18.586484 & 0.864491 & -0.280240 & -16.056588 \\
\hline
\end{tabular}

The magnitude of the active and reactive powers at different buses are observed when UPFC is not connected in the IEEE 14 Bus power transmission system and compared with the magnitude of the active and reactive powers when UPFC is connected in the IEEE 14 Bus system between the lines of 1 and 2 and tabulated below.

Table 4: power flow profile of IEEE 14 Bus with and without UPFC

\begin{tabular}{|c|c|c|c|c|c|c|}
\hline \multirow{2}{*}{ BUS CODE } & \multicolumn{3}{|c|}{$\begin{array}{c}\text { POWER FLOW BETWEEN LINES - } \\
\text { WITHOUT UPFC }\end{array}$} & \multicolumn{3}{|c|}{$\begin{array}{l}\text { POWER FLOW BETWEEN LINES - } \\
\text { WITHOUT UPFC }\end{array}$} \\
\hline & $\begin{array}{l}\text { REAL } \\
\text { POWER }\end{array}$ & $\begin{array}{l}\text { REACTIVE } \\
\text { POWER }\end{array}$ & LOSS & $\begin{array}{c}\text { REAL } \\
\text { POWER }\end{array}$ & $\begin{array}{l}\text { REACTIVE } \\
\text { POWER }\end{array}$ & LOSS \\
\hline $1-2$ & 1.609601 & 0.823090 & 0.057229 & 1.334390 & 0.610381 & 0.037778 \\
\hline $1-5$ & 0.758121 & 0.420985 & 0.037316 & 0.592468 & 0.284782 & 0.021573 \\
\hline $2-3$ & 0.733802 & 0.265613 & 0.030018 & 0.688326 & 0.228969 & 0.025130 \\
\hline $2-4$ & 0.575634 & 0.177098 & 0.022095 & 0.484944 & 0.123283 & 0.014784 \\
\hline $2-5$ & 0.425935 & 0.133966 & 0.011960 & 0.306342 & 0.071948 & 0.005774 \\
\hline $3-4$ & -0.238216 & -0.011711 & 0.004663 & -0.278804 & -0.026050 & 0.006054 \\
\hline $4-5$ & -0.625277 & -0.138474 & 0.006425 & -0.743629 & -0.173525 & 0.008563 \\
\hline $4-7$ & 0.290978 & 0.207632 & 0.000000 & 0.286526 & 0.200626 & -0.000000 \\
\hline $4-9$ & 0.166960 & 0.119137 & -0.000000 & 0.164406 & 0.115117 & 0.000000 \\
\hline $5-6$ & 0.427078 & 0.281386 & 0.000000 & 0.433580 & 0.279803 & 0.000000 \\
\hline
\end{tabular}




\section{International Journal of Advanced Research in Electrical, Electronics and Instrumentation Engineering}

(An ISO 3297: 2007 Certified Organization)

\section{Vol. 4, Issue 8, August 2015}

\begin{tabular}{|c|c|c|c|c|c|c|}
\hline $6-11$ & 0.064303 & 0.032752 & 0.000655 & 0.068402 & 0.034526 & 0.000682 \\
\hline $6-12$ & 0.077051 & 0.025706 & 0.001074 & 0.077533 & 0.025667 & 0.001002 \\
\hline $6-13$ & 0.173724 & 0.072840 & 0.003109 & 0.175646 & 0.073312 & 0.002929 \\
\hline $7-8$ & -0.000000 & -0.000000 & 0.000000 & 0.000000 & 0.000000 & 0.000000 \\
\hline $7-9$ & 0.290978 & 0.176161 & 0.000000 & 0.286526 & 0.172386 & 0.000000 \\
\hline $9-10$ & 0.061720 & 0.045562 & 0.000256 & 0.057625 & 0.043775 & 0.000210 \\
\hline $9-14$ & 0.101218 & 0.039624 & 0.002052 & 0.098307 & 0.038144 & 0.001785 \\
\hline $10-11$ & -0.028536 & -0.013117 & 0.000112 & -0.032586 & -0.014784 & 0.000135 \\
\hline $12-13$ & 0.014977 & 0.007471 & 0.000086 & 0.015531 & 0.007581 & 0.000084 \\
\hline $13-14$ & 0.050506 & 0.016111 & 0.000673 & 0.053164 & 0.017050 & 0.000686 \\
\hline
\end{tabular}

The magnitude of the voltages and power flows at different buses are observed when UPFC is not connected in the IEEE 5 Bus power transmission system and compared with the magnitude of the voltages when UPFC is connected in the IEEE 5 Bus system between the lines of 1 and 2 .

The waveforms are compared with and without UPFC in all parameters are tabulated below:

\section{WAVEFORMS OF IEEE 5 BUS WITH AND WITHOUT UPFC}

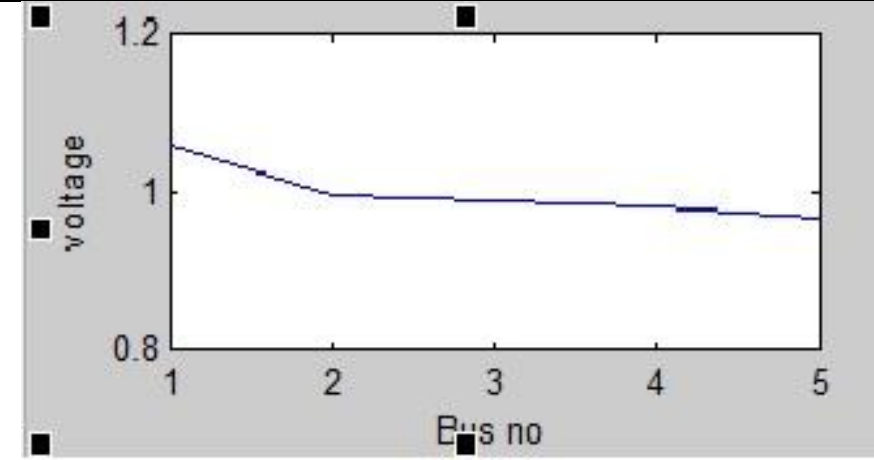

Fig.5.1 Shows the Bus Voltages without UPFC

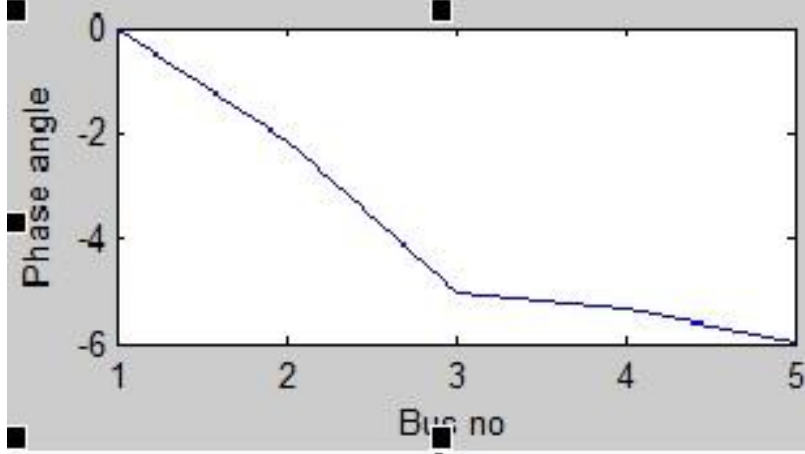

Fig.5.2 Shows the Phase angle without UPFC

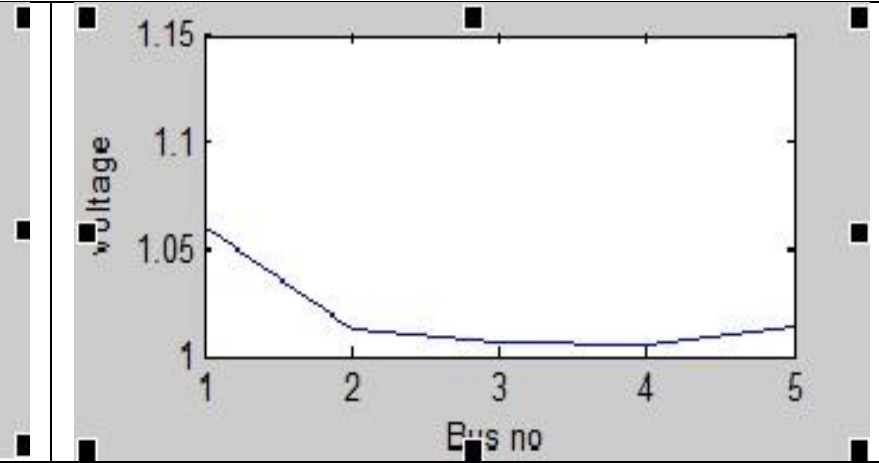

Fig.5.6 Shows the Bus Voltages with UPFC

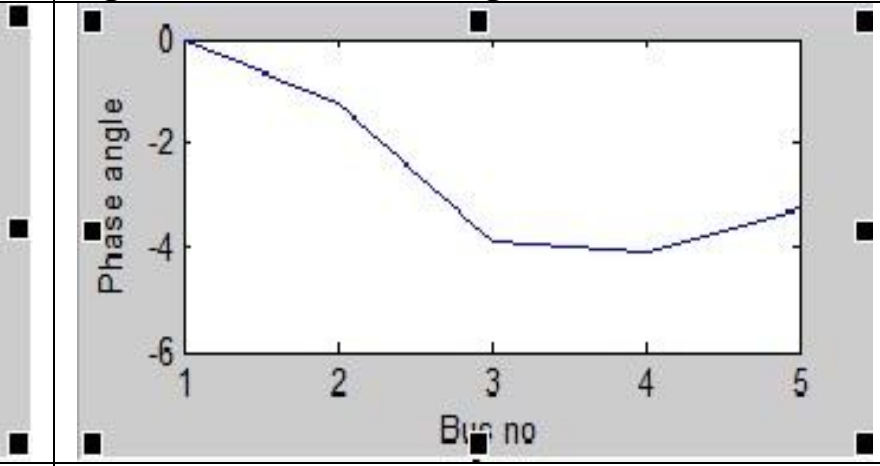

Fig. 5.7 Shows the Phase angle with UPFC 


\section{International Journal of Advanced Research in Electrical, Electronics and Instrumentation Engineering}

(An ISO 3297: 2007 Certified Organization)

\section{Vol. 4, Issue 8, August 2015}

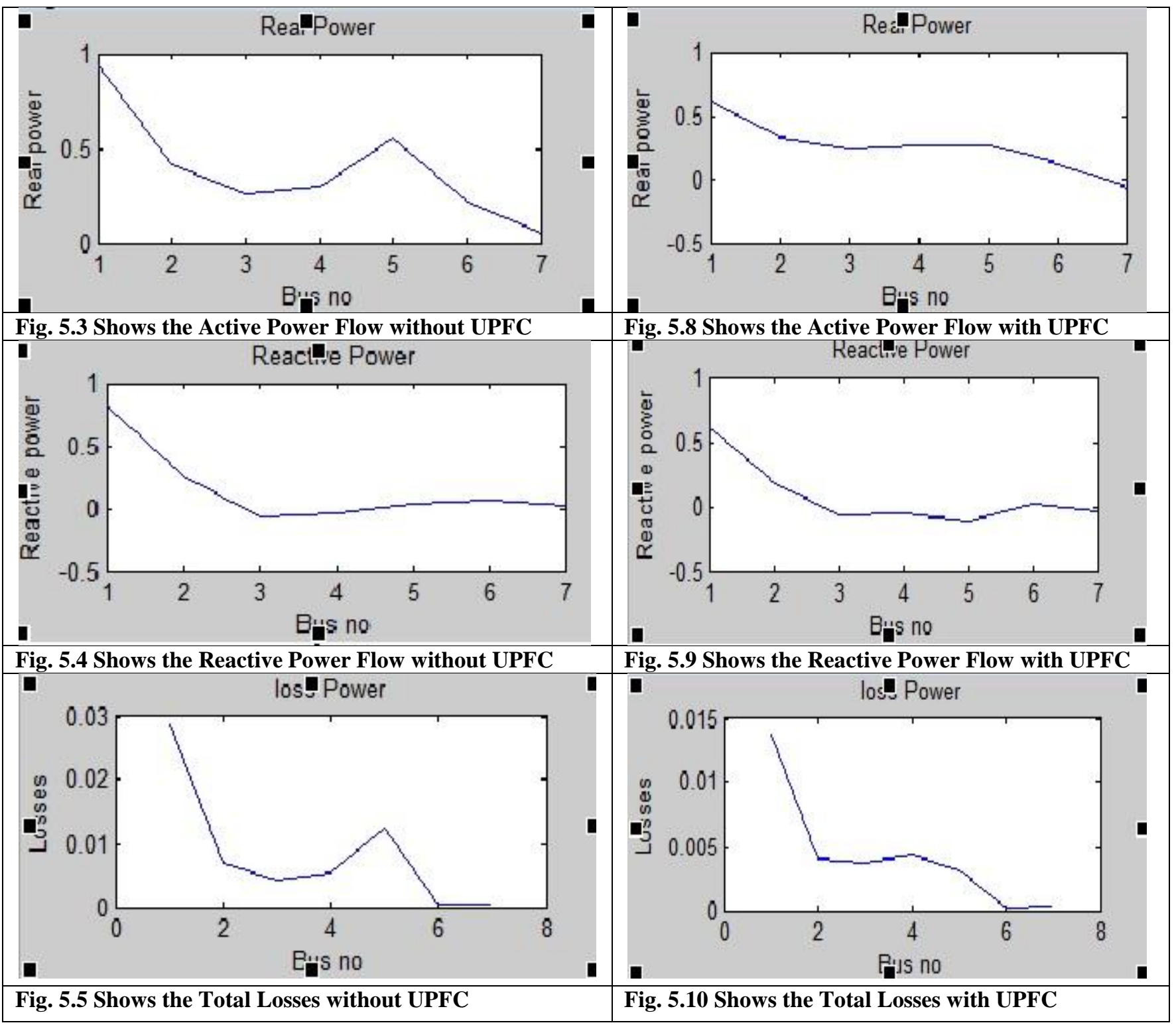

\section{CONCLUSION}

In this paper the UPFC Voltage Source Model (VSM) was utilized to research the execution of the Unified Power Flow Controller (UPFC) furthermore, in this manner the heap stream studies were finished by incorporating the Voltage Source Model of UPFC in the Newton Raphson (N-R) calculation. The N-R calculation has the capacity control the stream of force and voltage independently and in addition all the while. The outcome for an IEEE-5, IEEE-14 and IEEE-30 Bus framework has been exhibited above without and with UPFC and was looked at regarding Genuine and Reactive force stream and the Voltage extent. Hence forth it was watched that the UPFC controls the genuine and receptive force of the transports and the lines and it additionally controls the voltage of the transport inside determined breaking points, along these lines lessens the aggregate misfortunes in the lines.

The rudiments of FACTS gadget UPFC are talked about. Subsequently, an effortlessly justifiable UPFC model expected for OPF studies is determined and UPFC force stream comparisons are inferred. The displayed model is 


\title{
International Journal of Advanced Research in Electrical, Electronics and Instrumentation Engineering
}

\author{
(An ISO 3297: 2007 Certified Organization)
}

\section{Vol. 4, Issue 8, August 2015}

extremely adaptable; it considers different UPFC working modes. In spite of the fact that the Nabavi - Niaki and Iravani model has a few inconveniences, it offers ascend to more perplexing comparison.

\section{REFERENCES}

[1] Abbate L, Trovato M, Beeker C and Handschin E (2002), “Advanced Steady State Models of UPFC for Power Systems Studies”, IEEE, pp. $449-454$

[2] 2. Fuerte-Esquivel C R and Ache E (1997), "Unified Power Flow Controller: A Critical Comparison of Newton-Raphson UPFC Algorithm in Power Flow Studies", IEE Proc.-Genera. Transmit. Disturb. Vol. 144, No. 5.

[3] Fuerete-Esquivel C R and Acha E (1998), “Incorporation of UPFC Model in an Optimal Power Flow Using Newton's Method”, IEE Proc.-Gen. Transm. Disturb. Vol. 145, No. 3, pp. 336-344

[4] Fuerte-Esquivel C R, Acha E, and Ambriz-Perez H (2000), "Comprehensive Newton-Raphson UPFC Model for the Quadratic Power Flow Solution of Practical Power Networks", IEEE Trans. on Power Systems, Vol. 15, No. 1, pp. 102-109.

[5] Fuerte-Esquiivel C R and Acha E (1996), "Newton-Raphson Algorithm for the Reliable Solution of Large Power Networks with Embedded FACTS", IEE Proc.Ganev. Tvansnr. Distrib. Vol. 143, No. 5, pp. 447-454.

[6] Gyugyi L (1992), “Unified Power Flow Controller Concept for Flexible AC Transmission System”, IEE Proc., Vol. 139, No. 4, pp. 323-331.

[7] Gyugyi L et al. (1995), "The Unified Power Flow Controller: A New Approach to Power Transmission Control”, IEEE Trans on Power Delivery, Vol. 10, No. 2 , pp. 1085-1097.

[8] Hingorani N G (1988), "High Power Electronics and Flexible AC Transmission System”, IEEE Power Engineering Review, July, pp. 3-4

[9] Mehmet Tumay and Mete Vural A (2004), "Analysis and modelling of Unified power Flow Controller: Modification of Newton Raphson Algorithm and UserDefined modelinf Approach for power flow studies", The Arabian Journal for science and Engg.

[10] Noroozian M, Angquist L, Ghandhari M and Anderson G (1995), "Use of UPFC for Optimal Power Flow Control", IEEE iKTH Stockholm Power Tech Conference, Stockholm, Sweden, pp. 506-511.

[11] Nabavi-Niaki A and Iravani M R (1996), "Steady-State and Dynamic Models of Unified Power Flow Controller (UPFC) for Power System Studies", Presented at 1996 IEEE iPES Winter Meeting, pp. 447-454, Baltimore.

[12] Nabavi-Niaki M and Iravani R (1996), “Steady-State and Dynamic Models of Unified Power Flow”, IEEE Trans. on Power Systems, Vol. 11, No. 4, pp. 19371943. 13. Stagg N G and El-Abiad H A (1968), "Computer Methods in Power System Analysis”, McGraw-Hill Inc.

\section{BIOGRAPHY}

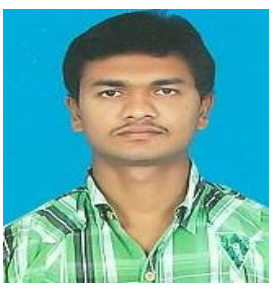

R. Venkata satish, He received B.Tech (Electrical and Electronics Engineering) from Jawaharlal Nehru Technological University, Anantapuram, in 2011 and pursuing M.Tech in the specialization of (Electrical power system) from Jawaharlal Nehru Technological University, Anantapuram. His area of interest in the field of power systems and Electrical machines.

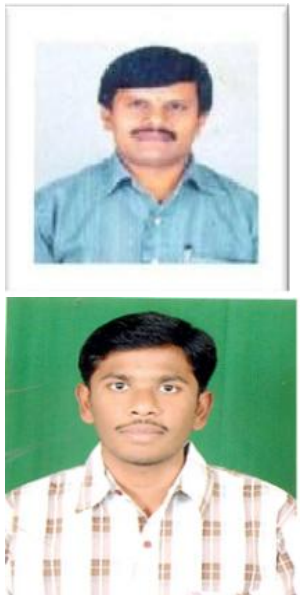

A.Hema sekhar, He received B.Tech in Electrical and Electronics Engineering from JNTU, Hyderabad, at Sree Vidyanikethan Engineering College, Rangampet; M.Tech (PSOC) from the S.V.University college of Engineering,Tirupati.He is currently working as Associate Professor \& Head of the Dept. of Electrical and Electronic Engineering, S.V.P.C.E.T,Puttur. His area of interest power systems, operation and control, distribution systems, electrical machines. , Power Stability

T.Suneel Kumar, Received B.Tech in Electrical and Electronics Engineering from JNTU, Hyderabad in 2006 and pursued M.E in the specialization of Power Electronics and Drives from PSG college of Technology, Anna University, Coimbatore in 2009. Presently working as Assistant Professor in Sree Vidyanikethan Engineering College, A. Rangampet, Tirupati. His areas of interest Power Electronic converters, Drives, FACTS controllers. 